Márcio Soares ${ }^{1}$, Suzana Margarete Ajeje Lobo $^{2}$, André Peretti Torelly ${ }^{3}$, Patricia Veiga de Carvalho Mello ${ }^{4}$, Ulisses Silva ${ }^{5}$, José Mário Meira Teles ${ }^{6}$, Eliézer Silva ${ }^{7}$, Pedro Caruso $^{8}$, Gilberto Friedman ${ }^{3,9}$, Paulo César Pereira de Souza ${ }^{10,11}$, Álvaro Réa-Neto ${ }^{12}$, Arthur Oswaldo Vianna ${ }^{13}$, José Raimundo Azevedo $^{14}$, Érico Vale ${ }^{15}$, Leila Rezegue ${ }^{16}$, Michele Godoy ${ }^{17}$, Marcelo Oliveira Maia ${ }^{18}$, Jorge Ibrain Figueira Salluh ${ }^{1}$, on behalf of the Brazilian Research in Intensive Care Network - BRICNet

1. Intensive Care Unit, Hospital de Câncer-I, Instituto Nacional de Câncer, Rio de Janeiro (RJ), Brazil. 2. Division of Critical Care Medicine, Department of Internal Medicine, Medical School and Hospital de Base, São José do Rio Preto (SP), Brazil.

3. Intensive Care Unit, Santa Casa de Misericórdia de Porto Alegre, Porto Alegre (RS), Brazil.

4. Intensive Care Unit, Universidade Estadual do Piauí, Teresina (PI), Brazil.

5. Intensive Care Unit, Hospital do Câncer de Barretos Fundaçáo Pio XII, Barretos (SP), Brazil.

6. Intensive Care Unit, Hospital Português, Salvador (BA), Brazil.

7. Intensive Care Unit, Hospital Israelita Albert

Einstein, Sảo Paulo (SP), Brazil.

8. Intensive Care Unit, Hospital A. C. Camargo, São

Paulo (SP), Brazil.

9. Intensive Care Unit, Universidade Federal do Rio Grande do Sul, Porto Alegre (RS), Brazil

10. Intensive Care Unit, Hospital de Clínicas Niterói, Niterói (RJ), Brazil.

11. Intensive Care Unit, Hospital de Clínicas Mario

Lioni, Duque de Caxias (RJ), Brazil.

12. Intensive Care Unit, Hospital de Clínicas da

Universidade Federal do Paraná, Curitiba (PR), Brazil.

13. Intensive Care Unit, Clínica São Vicente, Rio de Janeiro (RJ), Brazil.

14. Intensive Care Unit, Hospital São Domingos, São Luis (MA), Brazil.

15. Intensive Care Unit, Hospital Unimed Natal, Natal (RN), Brazil.

16. Intensive Care Unit, Hospital Porto Dias, Belém (PA), Brazil.

17. Intensive Care Unit, Hospital das Clínicas,

Universidade Federal de Pernambuco, Pernambuco (PE), Brazil.

18. Intensive Care Unit, Hospital Santa Luzia, Brasília (DF), Brazil.

The study was coordinated by the Instituto Nacional de Câncer, Rio de Janeiro, Brazil, on behalf of the Brazilian Research in Intensive Care Network - BRICNet.

Conflicts of interest: None.

Submitted on June 27, 2010

Accepted on August 12, 2010

Author for correspondence:

Márcio Soares

Instituto Nacional de Câncer - Centro de Tratamento

Intensivo - $10^{\circ}$ Andar

Pça. Cruz Vermelha, 23

Zip Code: 20230-130 - Rio de Janeiro (RJ), Brazil.

Phone: +55 (21) 2506-6120 -

Fax: +55 (21) 2294-8620

E-mail: marciosoaresms@yahoo.com.br

\section{Outcomes of cancer patients admitted to Brazilian intensive care units with severe acute kidney injury}

\author{
Ddesfecho de pacientes com câncer internados em unidades de \\ terapia intensiva brasileiras com lesáo renal aguda
}

\section{ABSTRACT}

Objectives: Critically ill cancer patients are at increased risk for acute kidney injury, but studies on these patients are scarce and were all single centered conducted in specialized intensive care units. The objective was to evaluate the characteristics and outcomes in a prospective cohort of cancer patients admitted to several intensive care units with acute kidney injury.

Methods: Prospective multicenter cohort study conducted in intensive care units from 28 hospitals in Brazil over a two-month period. Univariate and multivariate logistic regression were used to identify factors associated with hospital mortality.

Results: Out of all 717 intensive care unit admissions, 87 (12\%) had acute kidney injury and $36 \%$ of them received renal replacement therapy. Kidney injury developed more frequently in patients with hematological malignancies than in patients with solid tumors $(26 \%$ vs. $11 \%$, $P=0.003)$. Ischemia/shock (76\%) and sepsis $(67 \%)$ were the main contributing factor for and kidney injury was multifactorial in $79 \%$ of the patients. Hospital mortality was $71 \%$. General and renal-specific severity-of-illness scores were inaccurate in predicting outcomes for these patients. In a multivariate analysis, length of hospital stay prior to intensive care unit, acute organ dysfunctions, need for mechanical ventilation and a poor performance status were associated with increased mortality. Moreover, cancer-related characteristics were not associated with outcomes.

Conclusions: The present study demonstrates that intensive care units admission and advanced life-support should be considered in selected critically ill cancer patients with kidney injury.

Keywords: Kidney failure, acute; Dialysis; Neoplasms; Mortality; Critical illness; Multicenter study

\title{
INTRODUCTION
}

Critically ill patients with cancer are at increased risk for acute kidney injury (AKI). ${ }^{(1,2)}$ In addition, AKI is a complex issue, because it is usually multifactorial, occurring in the context of multiple organ failure and associated with high mortality rates. ${ }^{(3-10)}$ As studies from the 90 's reported mortality rates of up to $93 \%,{ }^{(11)}$ oncologists, intensivists, and nephrologists were reluctant in starting renal replacement therapy (RRT) in these patients. Nevertheless, in more recent studies, investigators from different centers have reported better survival rates, ${ }^{(6,8-10)}$ and that the diagnosis of a malignancy per se was no longer associated with a higher risk of death. ${ }^{(7,8)}$ 
Moreover, it was also demonstrated that renal function recovers in more than $80 \%$ of patients discharged alive from the intensive care unit (ICU). ${ }^{(9)}$ However, studies evaluating appropriately this subgroup of critically ill patients with cancer are still scarce and were all single centered conducted in specialized ICUs with potential implications to the generalization of results to nonspecialized units. ${ }^{(5-11)}$ Additionally, there is no information on the performance of prognostic scores in these patients. Therefore, we studied a prospective cohort of critically ill patients with cancer and AKI admitted to 28 ICUs in Brazil with three major aims: 1) to assess their characteristics and outcomes; 2) to identify factors associated with hospital mortality; and, 3) to evaluate the performance of two general and one renalspecific prognostic scores.

\section{METHODS}

\section{Design and setting}

Patients were selected from a multicenter prospective cohort study on the outcomes of patients with cancer admitted to 28 ICUs from Brazil, conducted between August $1^{\text {st }}$ and September $30^{\text {th }}, 2007 . .^{(12)}$ The study was coordinated by the Instituto Nacional de Câncer, Rio de Janeiro, Brazil, on behalf of the Brazilian Research in Intensive Care Network - BRICNet. ICUs participating in the BRICNet are located in a wide variety of hospital types (academic centers, private hospitals, nonacademic urban hospitals, etc.) from different Brazilian geographic regions. The complete list of investigators and centers is available at the end of the manuscript. The present study was strictly observational and every clinical decision (including to admit a patient to the ICU and to start RRT) was at the discretion of attending physicians. The study was approved by all local Institutional Review Boards and by the Brazilian National Ethics Committee, and informed consent was waived.

\section{Selection of participants}

During the study period, all patients with cancer aged $\geq 18$ years old presenting either with AKI or with acute on chronic kidney injury (ACKI) on the first $24 \mathrm{~h}$ of admission to the participating ICUs were evaluated. In the present study, only patients classified as Failure according to the RIFLE classification (acute three-fold increase in serum creatinine ( $\mathrm{SCr}$ ); a $\mathrm{SCr} \geq 4 \mathrm{mg} / \mathrm{dl}$ with an acute rise $>0.5 \mathrm{mg} / \mathrm{dl}$; urine output $<0.3 \mathrm{ml} /$ $\mathrm{kg}$ /hour in 24 hours; anuria observed in 12 hours;) or need for RRT were included. ${ }^{(13,14)}$ Patients in complete cancer remission for more than five years, readmissions and those with an ICU stay $<24 \mathrm{~h}$ were not evaluated. Patients with end-stage renal disease $(n=7)$ were also not considered. Patients with chronic kidney injury had a known glomerular filtration rate $<60 \mathrm{ml} / \mathrm{min} /$ per $1.73 \mathrm{~m}^{2}$ for at least three months. ${ }^{(15)}$ Oliguria was defined as urine output $<400 \mathrm{ml} /$ day.

\section{Data collection and definitions}

Data were collected using a specific and standardized case report form. All study documents, including a glossary with all definitions and procedures for data collection, were made available online throughout the study. The coordinating center was accessible for contact in case of any questions or problems during the phase of data collection.

Demographic, clinical and laboratory variables were prospectively collected during ICU admission, including hospital location before ICU admission, main diagnosis for ICU admission, comorbidities, ${ }^{(16)}$ performance status (PS) [Eastern Cooperative Oncology Group scale], ${ }^{(17)}$ contributing factors for AKI and cancer- and treatment-related data. The following scores were calculated: the third versions of the Simplified Acute Physiology Score (SAPS 3), ${ }^{(18)}$ and of the Mortality Probability Model $\left(\mathrm{MPM}_{0}\right.$-III), ${ }^{(19)}$ and Mehta's score. ${ }^{(20)}$ The predicted mortality derived from customized equation for countries from Central and South America (CSA) of SAPS 3 score was also estimated. ${ }^{(18)}$ Organ dysfunctions were evaluated using the Sequential Organ Failure Assessment (SOFA). ${ }^{(21)}$ Patients were classified based on the reason for ICU admission in medical, scheduled surgical and emergency surgical. Comorbidities were evaluated using the Adult Comorbidity Evaluation-27 (ACE-27), which grades a wide range of comorbid diseases and conditions according to the severity of organ decompensation and prognostic impact. ${ }^{(16)}$ Neutropenia was defined as a neutrophil count below $500 / \mathrm{mm}^{3}$. Sepsis was diagnosed according to the current definitions. ${ }^{(22)}$ Data on RRT procedures were not collected. Decisions to start, change the method, and cease RRT were taken together by the nephrologist and/or the intensivist responsible for the patient on an individual basis and according to the policies at each ICU. Vital status at hospital discharge was the main outcome.

\footnotetext{
Data management, presentation and statistical analysis

Data entry was centralized and performed by a single data manager using a Microsoft Access database
} 
(Microsoft Corporation, Redmond, WA, USA). Data consistency was assessed by a single author (M.S.) through a rechecking procedure of a $10 \%$ random sample of patients. Data were screened in detail by three investigators for missing information, implausible and outlying values, logical errors and insufficient details. In case of unconformity, local investigators were contacted to provide the requested information.

Standard descriptive statistics were used to describe the study population. Continuous variables were reported as mean \pm standard deviation or median $(25 \%$ $75 \%$ interquartile range, IQR). Univariate and multivariate logistic regression were used to identify factors associated with hospital mortality. ${ }^{(23)}$ Linearity between continuous variables and the dependent variable was assessed using locally weighted scatterplot smoothing (LOWESS). ${ }^{(23)}$ In case of nonlinearity, the variable was transformed accordingly. For categorical variables with multiple levels, the reference level was attributed to the one with the lowest probability of the dependent variable. Variables yielding $P$ values $<0.2$ by univariate analysis and those considered clinically relevant were entered in the multivariate analysis to estimate the independent association of each covariate with the dependent variable. Results were summarized as oddsratios (OR) and respective 95\% confidence intervals (CI). Possible interactions were tested. The area under the receiver-operating characteristic curve (AROC) was used to assess the models' discrimination; an AROC of 1.0 denotes perfect, while a value in the close to 0.50 indicates no apparent accuracy. ${ }^{(24)}$ AROC were compared using nonparametric statistics. ${ }^{(25)}$ The HosmerLemeshow goodness-of-fit test was used to evaluate agreement between the observed and expected results across all strata of probabilities of the outcome of interest (calibration). ${ }^{(23)}$ With this test, $P$ values $>0.05$ indicate a good fit for the model. Two-tailed $P$ values $<0.05$ were considered statistically significant.

\section{RESULTS}

\section{Characteristics of the study population}

From 717 patients admitted to the ICUs during the study period, 87 (12\%) fulfilled the eligibility criteria and constituted the study population. Frequency of AKI was higher in hematological malignancies [26\% $(13 / 50)]$ than in patients with solid tumors $[11 \%$ (74/667)] $(P=0.003)$. The most frequent type of malignancies were upper gastrointestinal $(\mathrm{n}=19,22 \%)$, urogenital $(n=13,15 \%$, lower gastrointestinal $(n=11$,
$13 \%)$, lymphomas $(n=7,8 \%)$ and leukemias $(n=5$, $6 \%)$. Only four $(5 \%)$ patients underwent bone marrow transplant (BMT) (autologous $=2$; allogenic $=2$ ). The main patients' characteristics and laboratory findings related to AKI are depicted in tables 1 and 2, respectively. Besides AKI, the major reasons for ICU admission were: severe sepsis/septic shock $(n=58,67 \%)$, acute respiratory failure (excluding septic patients) $(\mathrm{n}=11$, $13 \%)$, postoperative complications $(n=9,10 \%)$ and others $(\mathrm{n}=9,10 \%)$. Comorbidities were indentified in $69(79 \%)$ patients and the most frequent were: arterial hypertension $[n=38(44 \%)]$, diabetes mellitus $[n=11$ $(13 \%)]$, chronic pulmonary disease $[\mathrm{n}=8(9 \%)]$ and coronary artery disease $[n=7(8 \%)]$. Seventeen $(20 \%)$ patients had chronic kidney injury and $26(30 \%)$ patients had oliguria (Table 3 ). The main contributing factors for AKI were ischemia/shock (76\%) and sepsis (67\%); 69 (79\%) patients had >1 reason for the development of renal dysfunction (Table 3 ).

On the first day of ICU, 18 (21\%) required RRT. Out of the remaining 69 patients, $13(19 \%)$ received RRT thereafter after a median of 3 (2-6) ICU days. In general, patients who received RRT had more severe organ failures (SOFA score; $15.2 \pm 3.7$ vs. $11.5 \pm 3.3$ points, $P<0.001)$ and more frequently received mechanical ventilation $(71 \%$ vs. $41 \%, P=0.014)$ than patients with no need for RRT. There were no significant differences regarding age $(P=0.959)$, SAPS 3 scores $(P=0.681)$, comorbidities $(P=0.999)$, PS $(P=0.760)$, use of vasopressors $(P=0.126)$, type $(P=0.241)$ and status of the cancer $(P=0.391)$.

\section{Outcome analysis}

The ICU mortality was 61\% (53/87) and hospital mortality was $71 \%(62 / 87)$. Despite the lack of statistical significance, hospital mortality was higher in patients who received RRT later on during the ICU stay $(92 \%)$ in comparison to those who received RRT on the first day of ICU (78\%) and those who did not (64\%) $(P=0.105)$. End-of-life decisions (to withhold or to withstand therapies) were taken in 18 (23\%) patients and rates were twice higher in non-RRT then in RRT patients $(29 \%$ vs. $14 \%, P=0.167)$. Survivors had shorter lengths of stay in the hospital prior to ICU admission, higher severity of acute illness and organ dysfunctions and were more mechanically ventilated than non-survivors. Urine output was also higher in survivors (1110 (710-2455) $\mathrm{mL}$ vs. 850 (215-1536) $\mathrm{mL}, P=0.038)$. Comparisons among these groups are depicted in tables 1 and 2. 
The length of hospital stay prior to ICU, the SOFA score, performance status, need for mechanical ventilation, tumoral urinary tract obstruction, the need for dialysis and lactate levels were selected to enter into a multivariate analysis to identify predictive factors for hospital mortality. The final model is presented in table 4 and had both good calibration and discrimination. Gender, chronic renal failure, oliguria and type of ma- lignancy (hematological vs. solid tumor) were all forced individually into the final model and, in general the coefficients of other covariates did not change.

\section{Severity of illness scores}

The mean SAPS 3 score was $69.5 \pm 16.7$ points and, as expected was higher in decedents than in survivors (72.6 \pm 17.0 vs. $61.8 \pm 13.6$ points, $P=0.006$ ). The discrimi-

Table 1 - Patients' characteristics and comparisons between survivors and non-survivors. ${ }^{2}$

\begin{tabular}{|c|c|c|c|c|c|}
\hline Variables & $\begin{array}{c}\text { All patients } \\
(\mathrm{N}=87)\end{array}$ & $\begin{array}{c}\text { Survivors } \\
(\mathrm{N}=25 ; 29 \%) \\
\end{array}$ & $\begin{array}{c}\text { Non-survivors } \\
(\mathrm{N}=62 ; 71 \%)\end{array}$ & $\begin{array}{c}\text { Odds-ratio } \\
(95 \% \mathrm{CI})\end{array}$ & $\mathrm{p} \mathrm{value}^{\mathrm{b}}$ \\
\hline Age (years) & $62.1 \pm 15.9$ & $64.1 \pm 16.5$ & $61.4 \pm 15.8$ & $0.99(0.96-1.02)$ & 0.501 \\
\hline Male gender & $54(62 \%)$ & $18(72 \%)$ & $36(58 \%)$ & $0.54(0.20-1.48)$ & 0.225 \\
\hline Hospital stay before ICU admission (days) & $2(0-8)$ & $1(0-4)$ & $3(0-16)$ & $1.55(1.08-2.21)$ & 0.016 \\
\hline Medical admission & $64(74 \%)$ & $19(76 \%)$ & $45(73 \%)$ & $0.84(0.29-2.45)$ & 0.953 \\
\hline \multicolumn{6}{|l|}{ Type of cancer } \\
\hline Solid tumor & $74(85 \%)$ & $23(92 \%)$ & $52(82 \%)$ & 1.00 & \multirow[t]{2}{*}{0.332} \\
\hline Hematological malignancy & $13(15 \%)$ & $2(8 \%)$ & $11(18 \%)$ & $2.48(0.51-12.10)$ & \\
\hline \multicolumn{6}{|l|}{ Cancer status } \\
\hline Controlled / remission & $9(10 \%)$ & $4(16 \%)$ & $5(8 \%)$ & 1.00 & \multirow[t]{4}{*}{0.557} \\
\hline Active - newly-diagnosed & $45(33 \%)$ & $12(48 \%)$ & $33(53 \%)$ & $2.20(0.50-9.58)$ & \\
\hline Active - recurrence / progression & $33(38 \%)$ & $9(36 \%)$ & $24(39 \%)$ & $2.13(0.46-9.71)$ & \\
\hline Neutropenia & $11(13 \%)$ & $4(16 \%)$ & $7(11 \%)$ & $0.69(0.18-2.52)$ & \\
\hline \multicolumn{6}{|l|}{ Performance status } \\
\hline $0-1$ & $36(41 \%)$ & $15(60 \%)$ & $21(34 \%)$ & 1.00 & \multirow[t]{2}{*}{0.046} \\
\hline $2-4$ & $51(59 \%)$ & $10(40 \%)$ & $41(66 \%)$ & $2.93(1.12-7.63)$ & \\
\hline \multicolumn{6}{|l|}{ Comorbidity score (ACE-27) } \\
\hline None-mild & $38(44 \%)$ & $9(36 \%)$ & $29(47 \%)$ & 1.00 & \multirow[t]{2}{*}{0.498} \\
\hline Moderate-severe & $19(56 \%)$ & $16(64 \%)$ & $33(53 \%)$ & $0.64(0.25-1.66)$ & \\
\hline Acute on chronic renal failure & $17(20 \%)$ & $6(24 \%)$ & $11(18 \%)$ & $0.68(0.22-2.11)$ & 0.713 \\
\hline SOFA score (points) & $12.8 \pm 3.8$ & $10.9 \pm 2.9$ & $13.6 \pm 3.9$ & $1.27(1.07-1.49)$ & $<0.001$ \\
\hline SOFA score (excluding renal points) & $10.5 \pm 3.6$ & $8.5 \pm 2.7$ & $11.3 \pm 3.7$ & $1.33(1.11-1.59)$ & $<0.001$ \\
\hline SAPS 3 score (points) & $69.5 \pm 16.7$ & $61.8 \pm 13.6$ & $72.6 \pm 17.0$ & $1.04(1.01-1.08)$ & 0.006 \\
\hline Mechanical ventilation & $45(52 \%)$ & $5(20 \%)$ & $40(65 \%)$ & $7.27(2.40-22.07)$ & $<0.001$ \\
\hline Vasopressors & $48(55 \%)$ & $14(44 \%)$ & $37(60 \%)$ & $1.88(0.74-4.82)$ & 0.275 \\
\hline Sepsis & $58(67 \%)$ & $17(68 \%)$ & $41(66 \%)$ & $0.92(0.34-2.48)$ & 0.999 \\
\hline Tumoral urinary tract obstruction & $12(14 \%)$ & $6(24 \%)$ & $6(10 \%)$ & $0.34(0.10-1.18)$ & 0.159 \\
\hline Oliguria & $26(30 \%)$ & $5(20 \%)$ & $21(34 \%)$ & $2.05(0.67-6.23)$ & 0.301 \\
\hline \multicolumn{6}{|l|}{ Start of dialysis } \\
\hline No & $56(64 \%)$ & $20(80 \%)$ & $36(58 \%)$ & 1.00 & \multirow[t]{3}{*}{0.147} \\
\hline On the $1^{\text {st }}$ day of ICU & $18(21 \%)$ & $4(16 \%)$ & $14(23 \%)$ & $1.94(0.56-6.71)$ & \\
\hline During ICU admission & $13(15 \%)$ & $1(4 \%)$ & $12(19 \%)$ & $6.67(0.81-55.1)$ & \\
\hline ICU LOS (days) & $6(3-13)$ & $3(4-10)$ & $7(3-17)$ & NA & 0.351 \\
\hline Hospital LOS (days) & $18(8-33)$ & $18(12-31)$ & $17(5-13)$ & NA & 0.353 \\
\hline
\end{tabular}

${ }^{a}$ Results expressed as mean \pm SD, median (IQR), $\mathrm{n}(\%)$.

${ }^{\mathrm{b}}$ Comparison between survivors and non-survivors.

CI - confidence interval; ICU - intensive care unit; LOS - length of stay; SAPS-Simplified Acute Physiology Score; SOFA - Sequential Organ Failure Assessment; ACE-27 - Adult Comorbidity Evaluation; NA - not applicable. 
Table 2 - Admission laboratory data related to renal function and comparisons between hospital survivors and non-survivors ${ }^{\mathrm{a}}$

\begin{tabular}{lcccc}
\hline Variables & $\begin{array}{c}\text { All patients } \\
(\mathrm{N}=87)\end{array}$ & $\begin{array}{c}\text { Survivors } \\
(\mathrm{N}=25 ; 29 \%)\end{array}$ & $\begin{array}{c}\text { Non-survivors } \\
(\mathrm{N}=62 ; 71 \%)\end{array}$ & $\mathrm{p}^{\text {p value }}{ }^{\mathrm{b}}$ \\
\hline Creatinine $(\mathrm{mg} / \mathrm{dL})$ & $2.2(1.5-3.3)$ & $2.3(1.9-3.4)$ & $2.1(1.4-2.9)$ & 0.048 \\
Urea $(\mathrm{mg} / \mathrm{dL})$ & $62(28-95)$ & $60(18-98)$ & $64(25-91)$ & 0.840 \\
$\mathrm{HCO}_{3}^{-}$concentration mEq/L) & $17.3(14.1-20.7)$ & $16.4(14.6-14.6-18.6)$ & $18.3(14.0-22.0)$ & 0.317 \\
Lactate $(\mathrm{mmol} / \mathrm{L})$ & $2.2(1.2-4.3)$ & $1.6(0.9-3.4)$ & $2.5(1.3-4.6)$ & 0.067 \\
Sodium $(\mathrm{mEq} / \mathrm{L})$ & $136(133-141)$ & $135(131-139)$ & $138(133-144)$ & 0.047 \\
Potassium $(\mathrm{mEq} / \mathrm{L})$ & $4.5(3.7-5.4)$ & $4.9(4.1-5.7)$ & $4.2(3.6-5.3)$ & 0.178 \\
\hline
\end{tabular}

a Results expressed as median (IQR).

${ }^{\mathrm{b}}$ Comparison between survivors and non-survivors.

Table 3 - Main associated factors of acute kidney injury $(\mathbf{n}=87)^{\mathrm{a}}$

\begin{tabular}{ll}
\hline & $\mathrm{N}(\%)$ \\
\hline Ischemia / shock & $66(76)$ \\
Sepsis & $58(67)$ \\
$\begin{array}{l}\text { Major surgery prior to ICU } \\
\text { admission }\end{array}$ & $27(31)$ \\
Urinary tract obstruction (cancer & $12(14)$ \\
related) & \\
Radiocontrast / nephrotoxins & $7(8)$ \\
Acute tumor lysis syndrome & $2(2)$ \\
Multiple myeloma & $1(1)$ \\
Unknown / other & $4(5)$ \\
\hline
\end{tabular}

a patient could have more than one associated condition.

ICU - intensive care unit. native abilities of SAPS 3, MPM - III and Mehta's scores were uniformly poor for all models and AROC ranged from 0.60 to 0.68 . MPM - -III and SAPS 3 tended to underestimate mortality, while Mehta’s score tended to overestimate it. Performances of the models are presented on Table 5. The AROC of the final model $[0.84,95 \% \mathrm{CI}=0.75-0.92)]$ was significantly higher than those of SAPS $3(P=0.013)$, MPM0-III $(P=0.001)$ and Mehta's $(P=0.009)$ scores.

\section{DISCUSSION}

Depending on the studied population, up to half of cancer patients experiences AKI and/or requires RRT while in the ICU. ${ }^{(5-11)}$ In the present study, $12 \%$ of pa-

Table 4 - Multivariate analysis of factors associated with hospital mortality $(\mathrm{n}=87)^{\mathrm{a}}$

\begin{tabular}{llll}
\hline Variables & Coefficient & Odds-ratios (95\% CI) & p value \\
\hline Hospital days prior to ICU admission (Ln) & 0.439 & $1.55(1.03-2.34)$ & 0.036 \\
PS 2-4 & 1.175 & $3.23(1.03-10.17)$ & 0.044 \\
Mechanical ventilation & 1.470 & $4.35(1.18-15.97)$ & 0.027 \\
SOFA Score (points) & 0.192 & $1.21(0.98-1.49)$ & 0.073 \\
Constant & -3.004 & & \\
\hline
\end{tabular}

aROC - $0.84(95 \% \mathrm{CI}=0.75-0.92)$; goodness-of-fit test $\left(\chi^{2}=4.218, \mathrm{p}=0.754\right)$

CI - confidence interval; ICU - intensive care unit; AROC - area under receiver operating characteristic curve; PS - performance status.

Table 5 - Area under receiver operating characteristic curves, Hosmer-Lemeshow goodness-of-fit C-statistics and standardized mortality ratios for the different prognostic models $(n=87)^{\mathrm{a}}$

\begin{tabular}{lccccc}
\hline Prognostic model & AROC $(95 \%$ CI $)$ & \multicolumn{2}{c}{ Goodness-of-fit C-test } & \multicolumn{2}{c}{ Predicted mortality } \\
& & $\chi 2$ & P value & SMR (95\% CI) \\
\hline MPM -III & $0.60(0.67-0.75)$ & 17.889 & 0.022 & $20.6 \pm 18.0$ & $3.44(2.23-5.31)$ \\
SAPS 3 & $0.68(0.57-0.80)$ & 4.238 & 0.752 & $52.4 \pm 26.6$ & $1.35(1.06-1.71)$ \\
SAPS 3 (CSA) & $0.68(0.57-0.80)$ & 5.069 & 0.651 & $62.8 \pm 27.7$ & $1.14(0.93-1.42)$ \\
Mehta's score & $0.66(0.54-0.78)$ & 7.297 & 0.505 & $80.8 \pm 21.2$ & $0.87(0.74-1.03)$ \\
\hline
\end{tabular}

a The hospital mortality was $71 \%$.

AROC - area under receiver operating characteristic curve; CI - confidence interval, SD - standard deviation; SMR - standardized mortality rate, CMM - Cancer Mortality Model; MPM - Mortality Probability Model; SAPS - Simplified Acute Physiology Score; CSA - customized equation for countries from Central and South America. 
tients were admitted to the ICU with AKI and, in accordance to Taccone et al., ${ }^{(26)}$ the frequency was higher in patients with hematological malignancies than in patients with solid tumors ( $26 \%$ vs. $11 \%, P=0.003$ ). As also previously demonstrated, multiple causes for AKI were present in $79 \%$ patients. However, cancer-related causes for AKI were identified in less than $20 \%$ of them. To our knowledge, this is the first study to report the characteristics and outcomes of ICU patients with AKI selected from a multicenter database. Furthermore, in contrast to previous reports, studied patients were also enrolled in non-specialized ICUs.

Although the observed mortality rate seems higher than those reported in non-cancer patients, ${ }^{(1,27)}$ survival rates were quite acceptable and similar to those found in more recent reports from specialized ICUs. ${ }^{(6-10)}$ The main outcome predictors were a compromised performance status and the need for mechanical ventilation. Moreover, our results corroborate the evidence that the characteristics related to the underlying malignancy should not guide the decision-making process to admit a patient to the ICU or to start RRT.

Another remarkable finding of our study is related to the timing of AKI. The duration of hospital stay before ICU admission was an independent predictor of death. In addition, mortality rate was $91 \%$ in patients requiring RRT beyond the first day of ICU. While these findings might identify a subgroup of patients in whom AKI developed because implemented treatments were ineffective, on the other hand, they also might suggest potential benefits of early institution of organ support including RRT. In the study of Soares et al., the outcomes of patients who required RRT after the first day of ICU were considerably worse and no patient who required it beyond the fourth day survived. ${ }^{(9)}$ Darmon et al. also demonstrated that renal function deterioration after ICU admission was independently associated with mortality in cancer patients. ${ }^{(8)}$ Nonetheless, as information on the decision to start and cease RRT was not collected in the present study, caution is certainly needed in the interpretation of these data. In addition, the frequency of EOL decisions was twice higher in non-dialyzed patients, thus potential selection biases cannot be ruled out. However, the proportion of patients with AKI receiving RRT in our study is similar to those reported in literature. ${ }^{(5,9,10)}$

In multivariate analyses, in addition to the duration of hospital stay before ICU admission, the need for mechanical ventilation, the severity of associated organ dysfunctions and a compromised performance status were also associated with a lower probability of survival. All these variables are well known major outcome predictors not only in critically ill patients with cancer ${ }^{(8,9,12)}$ but also in general populations of ICU patients with AKI. ${ }^{(27,28)}$

The present study has also the merit of having performed the first external validations of more recent prognostic scores in patients with cancer with AKI, and both SAPS 3 and MPM - -III were inaccurate in predicting outcomes by underestimating mortality. General prognostic scores are known to underestimate mortality when used in patients with AKI at ICU admission. ${ }^{(29)}$ On the opposite, the use of a specific score for patients with AKI also resulted in poor discrimination by overestimating mortality. The analysis of calibration should however be interpreted with prudence, because the relatively small sample size imposed limitations to more appropriately evaluate this parameter. Although the analysis of discrimination seems to be less affected by sample sizes than calibration, ${ }^{(30)}$ external validation of prognostic models for critically ill patients requires substantial sample sizes. ${ }^{(31)}$

Nevertheless, many limitations must be taken into consideration in our study. First, despite of the multicenter and prospective design, a relatively low number of patients were evaluated, hence the lack of statistical power might have accounted for the lack of association between some variables and mortality. However, as the knowledge on ICU patients with cancer is increasing rapidly, a two-month duration was planned a priori to avoid potential biases related to changes in patterns of care. In addition, the fact that patients from non-specialized ICUs were also evaluated, we believe that our results may be more representative of the practice in general hospitals and therefore more suitable to generalization. Second, the present study was underpowered to evaluate patients with hematological malignancies and those who underwent BMT patients. Although this seems not to be the case for non-BMT patients with hematological malignancies and patients who underwent autologous BMT, ${ }^{(7)}$ we consider that allogenic BMT patients should be studied in separate and they have peculiarities that differentiate them in terms of prognosis and mortality in these patients remains exceedingly high particularly when RRT is needed. ${ }^{(5,7)}$ Finally, information on RRT indications and modes were not systematically collected, and this topic deserves to be evaluated in future multicenter studies. 


\section{CONCLUSIONS}

The present multicenter study confirmed that AKI in critically ill patients with cancer is frequent, usually multifactorial and still associated high mortality rates. On the other hand, the current study also suggests that ICU admission and RRT should be considered in selected patients. Mortality in these patients is mostly dependent on the severity of acute illness and the performance status, rather than cancer-related characteristics.

Participating centers and investigators: Bahia: Hospital Português (José Mário Meira Teles). Distrito Federal: Hospital Santa Luzia (Marcelo de Oliveira Maia). Espírito Santo: Vitória Apart Hospital (Cláudio Piras). Maranhão: Hospital São Domingos - Sáo Luís (José Raimundo Araújo de Azevedo, Widlani Sousa Silva) Minas Gerais: Hospital Mater Dei - Belo Horizonte (Frederico Bruzzi Carvalho). Pará: Hospital Porto Dias - Belém (Leila Rezegue, Rômulo Nina Paes). Paraná: Hospital de Clínicas - UFPR (Álvaro Réa Neto, Nazah C M Youssef). Pernambuco: Hospital de Clínicas - UFPE (Michele Maria Gonçalves de Godoy, Cláudia Ângela Vilela de Almeida, Roberto Barreto Campello). Piauí: Hospital de Terapia Intensiva - Teresina (Patrícia M. Veiga de C. Mello, Lina Melo). Rio de Janeiro: Instituto Nacional de Câncer - Hospital do Câncer I (Márcio Soares, Jorge I. F. Salluh); Instituto Nacional de Câncer - Hospital do Câncer II (José Jorge Soares Netto, Alexandre de Marca; Rodrigo Hatum; Frederico Muller; Pedro Tibúrcio Nagles; Wlademir Gonzalez); Hospital de Clínicas de Niterói (Paulo César Pereira de Souza, Cláudio Monteiro, Darwin Prado, Moyzés Damasceno); Hospital Mario Lioni - Duque de Caxias (Paulo C. P. Souza, Pedro Paulo Galhardo, Guilherme Nossar); Hospital Pasteur (Bruno da Silva Ferreira, Vicente Cés de Souza Dantas); Hospital Samaritano (Aline Castro, Ricardo Lima); Hospital CardioTrauma (Marcos Freitas Knibel, Robson Dantas Santana); Clínica São Vicente (Arthur Vianna, Alessandra Alves); Hospital São Lucas (Marcos Freitas Knibel, Eduardo Xavier). Santa Catarina: Hospital São José - Criciúma (Felipe Dal-Pizzol, Cristiane Ritter). São Paulo: Hospital A. C. Camargo (Pedro Caruso, Valdelis Novis Okamoto, Lúcio Souza dos Santos); Fundação Pio XII - Hospital do Câncer de Barretos (Ulysses V. A. Silva, Rosana D. S. Almeida, Richard S. P. Silva); Hospital Sírio Libanês (Luciano C. Pontes de Azevedo, Guilherme P. Schettino); Hospital Israelita Albert Einstein (Eliezer Silva, Alexandre Biasi Cavalcante, Miquéias Martins Lima Silva); Hospital de Base - Faculdade Regional de Medicina de São José do Rio Preto (Suzana Margareth Ajeje Lobo); Hospital do Servidor Público Estadual (Ed- erlon Alves de Carvalho Rezende). Rio Grande do Norte: Hospital Unimed Natal (Érico de Lima Vale). Rio Grande do Sul: Santa Casa de Misericórdia de Porto Alegre - Pavilhão Central (Gilberto Friedman, Jorge Amilton Hoher); Santa Casa de Misericórdia de Porto Alegre - Hospital Santa Rita (André Peretti Torelly).

Acknowledgments: We are indebt with the Instituto Nacional de Câncer, specially the Department of Clinical Research, and CNPq for all the support.

Financial support: Supported by Instituto Nacional de Câncer. Dr. Soares is supported in part by individual research grants from $\mathrm{CNPq}$.

\section{RESUMO}

Objetivos: Pacientes com câncer criticamente enfermos têm maior risco de lesão renal aguda, mas estudos envolvendo estes pacientes são escassos, e todos em centros únicos e realizados em unidades de terapia intensiva especializadas. $\mathrm{O}$ objetivo deste estudo foi avaliar as características e desfechos em uma coorte prospectiva de pacientes de câncer internados em diversas unidades de terapia intensiva com lesão renal aguda.

Métodos: Estudo prospectivo multicêntrico de coorte realizado em unidades de terapia intensiva de 28 hospitais brasileiros em um período de dois meses. Foram utilizadas regressóes logísticas univariada e multivariada para identificar os fatores associados a mortalidade hospitalar.

Resultados: Dentre todas as 717 internaçôes a unidades de terapia intensiva, 87 (12\%) tiveram lesão renal aguda e 36\% deles receberam terapia de substituição renal. A lesão renal se desenvolveu mais frequentemente em pacientes com neoplasias hematológicas do que em pacientes com tumores sólidos $(26 \%$ $\mathrm{x} 11 \% ; \mathrm{p}=0,003)$. Isquemia/choque $(76 \%)$ e sepse $(67 \%)$ foram os principais fatores associados à lesão renal, e esta foi multifatorial em $79 \%$ dos pacientes. A letalidade hospitalar foi de $71 \%$. Os escores de gravidade gerais e especificos para pacientes com lesão renal, foram imprecisos para predizer o prognóstico nestes pacientes. $\mathrm{Na}$ análise multivariada, a duração da internação hospitalar antes da unidade de terapia intensiva, disfunçóes orgânicas agudas, necessidade de ventilação mecânica e um performance status comprometido associaram-se à maior letalidade. Mais ainda, características relacionadas ao câncer não se associaram com os desfechos.

Conclusóes: $\mathrm{O}$ presente estudo demonstra que internação na unidade de terapia intensiva e suporte avançado à vida devem ser considerados em pacientes selecionados de câncer criticamente enfermos com lesão renal.

Descritores: Insuficiência renal aguda; Diálise; Neoplasias; Mortalidade; Estado terminal; Estudo multicêntrico 


\section{REFERENCES}

1. Chawla LS, Abell L, Mazhari R, Egan M, Kadambi N, Burke $\mathrm{HB}$, et al. Identifying critically ill patients at high risk for developing acute renal failure: a pilot study. Kidney Int. 2005;68(5):2274-80.

2. Bagshaw SM, Laupland KB, Doig CJ, Mortis G, Fick GH, Mucenski M, et al. Prognosis for long-term survival and renal recovery in critically ill patients with severe acute renal failure: a population-based study. Crit Care. 2005;9(6):R700-9.

3. Lameire N, Van Biesen W, Vanholder R. Acute renal problems in the critically ill cancer patient. Curr Opin Crit Care. 2008;14(6):635-46.

4. Darmon M, Ciroldi M, Thiery G, Schlemmer B, Azoulay E. Clinical review: specific aspects of acute renal failure in cancer patients. Crit Care. 2006;10(2):211. Review.

5. Létourneau I, Dorval M, Bélanger R, Légaré M, Fortier L, Leblanc M. Acute renal failure in bone marrow transplant patients admitted to the intensive care unit. Nephron. 2002;90(4):408-12

6. Berghmans T, Meert AP, Markiewicz E, Sculier JP. Continuous venovenous haemofiltration in cancer patients with renal failure: a single-centre experience. Support Care Cancer. 2004;12(5):306-11.

7. Benoit DD, Hoste EA, Depuydt PO, Offner FC, Lameire $\mathrm{NH}$, Vandewoude $\mathrm{KH}$, et al. Outcome in critically ill medical patients treated with renal replacement therapy for acute renal failure: comparison between patients with and those without haematological malignancies. Nephrol Dial Transplant. 2005;20(3):552-8.

8. Darmon M, Thiery G, Ciroldi M, Porcher R, Schlemmer B, Azoulay E. Should dialysis be offered to cancer patients with acute kidney injury? Intensive Care Med. 2007;33(5):765-72.

9. Soares M, Salluh JI, Carvalho MS, Darmon M, Rocco JR, Spector N. Prognosis of critically ill patients with cancer and acute renal dysfunction. J Clin Oncol. 2006; 24(24):4003-10.

10. Vieira JM Jr, Castro I, Curvello-Neto A, Demarzo S, Caruso P, Pastore L Jr, et al. Effect of acute kidney injury on weaning from mechanical ventilation in critically ill patients. Crit Care Med. 2007; 35(1):184-91.

11. Lanore JJ, Brunet F, Pochard F, Bellivier F, Dhainaut JF, Vaxelaire JF, et al. Hemodialysis for acute renal failure in patients with hematologic malignancies. Crit Care Med. 1991;19(3):346-51.

12. Soares M, Caruso P, Silva E, Teles JM, Lobo SM, Friedman G, Dal Pizzol F, Mello PV, Bozza FA, Silva UV, Torelly AP, Knibel MF, Rezende E, Netto JJ, Piras C, Castro A, Ferreira BS, Réa-Neto A, Olmedo PB, Salluh JI; Brazilian Research in Intensive Care Network (BRICNet). Characteristics and outcomes of patients with cancer requiring admission to intensive care units: a prospective multicenter study. Crit Care Med. 2010;38(1):9-15.
13. Bellomo R, Ronco C, Kellum JA, Mehta RL, Palevsky P; Acute Dialysis Quality Initiative workgroup. Acute renal failure - definition, outcome measures, animal models, fluid therapy and information technology needs: the Second International Consensus Conference of the Acute Dialysis Quality Initiative (ADQI) Group. Crit Care. 2004; 8(4):R204-12. Review.

14. Mehta RL, Kellum JA, Shah SV, Molitoris BA, Ronco C, Warnock DG, Levin A; Acute Kidney Injury Network. Acute Kidney Injury Network: report of an initiative to improve outcomes in acute kidney injury. Crit Care. 2007; 11(2):R31.

15. National Kidney Foundation. K/DOQI clinical practice guidelines for chronic kidney disease: evaluation, classification, and stratification. Am J Kidney Dis. 2002;39(2 Suppl 1):S1-266.

16. Piccirillo JF. Adult Comorbidity Evaluation-27. Comorbidity data collection form [Internet]. 2001. [cited 2010 Ago 19]. Available from: http://oto.wustl.edu/ clinepi/downloads.html.

17. Zubrod CG, Schneiderman M, Frei III E, Brindley C, Gold GL, Shnider B, et al. Appraisal of methods for the study of chemotherapy of cancer in man: comparative therapeutic trial of nitrogen mustard and triethylene thiophosphoramide. J Chron Dis 1960;11:7-33.

18. Moreno RP, Metnitz PG, Almeida E, Jordan B, Bauer P, Campos RA, Iapichino G, Edbrooke D, Capuzzo M, Le Gall JR; SAPS 3 Investigators. SAPS 3--From evaluation of the patient to evaluation of the intensive care unit. Part 2: Development of a prognostic model for hospital mortality at ICU admission. Intensive Care Med. 2005;31(10):134555. Erratum in: Intensive Care Med. 2006;32(5):796.

19. Higgins TL, Teres D, Copes WS, Nathanson BH, Stark M, Kramer AA. Assessing contemporary intensive care unit outcome: an updated Mortality Probability Admission Model (MPM0-III). Crit Care Med. 2007;35(3):827-35.

20. Mehta RL, Pascual MT, Gruta CG, Zhuang S, Chertow GM. Refining predictive models in critically ill patients with acute renal failure. J Am Soc Nephrol. 2002;13(5):1350-7.

21. Vincent JL, Moreno R, Takala J, Willatts S, De Mendonça A, Bruining H, et al. The SOFA (Sepsis-related Organ Failure Assessment) score to describe organ dysfunction/ failure. On behalf of the Working Group on Sepsis-Related Problems of the European Society of Intensive Care Medicine. Intensive Care Med. 1996;22(7):707-10.

22. Levy MM, Fink MP, Marshall JC, Abraham E, Angus D, Cook D, Cohen J, Opal SM, Vincent JL, Ramsay G; SCCM/ESICM/ACCP/ATS/SIS. 2001 SCCM/ ESICM/ACCP/ATS/SIS International Sepsis Definitions Conference. Crit Care Med. 2003;31(4):1250-6.

23. Hosmer DW, Lemeshow S. Applied logistic regression. 2nd ed. New York: Wiley; 2000.

24. Hanley JA, McNeil BJ. The meaning and use of the area under a receiver operating characteristic (ROC) curve. 
Radiology. 1982;143(1):29-36.

25. DeLong ER, DeLong DM, Clarke-Pearson DL. Comparing the areas under two or more correlated receiver operating characteristic curves: a nonparametric approach. Biometrics. 1988;44(3):837-45.

26. Taccone FS, Artigas AA, Sprung CL, Moreno R, Sakr Y, Vincent JL. Characteristics and outcomes of cancer patients in European ICUs. Crit Care. 2009;13(1):R15.

27. Uchino S, Kellum JA, Bellomo R, Doig GS, Morimatsu H, Morgera S, Schetz M, Tan I, Bouman C, Macedo E, Gibney N, Tolwani A, Ronco C; Beginning and Ending Supportive Therapy for the Kidney (BEST Kidney) Investigators. Acute renal failure in critically ill patients: a multinational, multicenter study. JAMA. 2005;294(7): 813-8.

28. Maccariello E, Soares M, Valente C, Nogueira L, Valença RV, Machado JE, Rocha E. RIFLE classification in patients with acute kidney injury in need of renal replacement therapy. Intensive Care Med. 2007;33(4):597-605.

29. Uchino S, Bellomo R, Morimatsu H, Morgera S, Schetz M, Tan I, Bouman C, Macedo E, Gibney N, Tolwani A, Doig GS, Oudemans van Straaten H, Ronco C, Kellum JA; Beginning and Ending Supportive Therapy for the Kidney (B.E.S.T. Kidney) Investigators. External validation of severity scoring systems for acute renal failure using a multinational database. Crit Care Med. 2005;33(9):1961-7.

30. Zhu BP, Lemeshow S, Hosmer DW, Klar J, Avrunin J, Teres D. Factors affecting the performance of the models in the Mortality Probability Model II system and strategies of customization: a simulation study. Crit Care Med. 1996;24(1):57-63.

31. Peek N, Arts DG, Bosman RJ, van der Voort PH, de Keizer NF. External validation of prognostic models for critically ill patients required substantial sample sizes. J Clin Epidemiol. 2007;60(5):491-501. 